\title{
Facilitation of Developmental Tasks in Prisons: Applying the Method of Human-Centred Co-evaluation
}

\section{Laura Seppänen, Heli Heikkilä, Anu Kajamaa, Päivikki Lahtinen, and Hilkka Ylisassi}

\section{Introduction}

The changes and transformations of work call for a culture of collaboration, innovation and learning in prisons and elsewhere. To promote

L. Seppänen $(\varangle) \cdot$ H. Heikkilä · H. Ylisassi

Finnish Institute of Occupational Health, Helsinki, Finland

e-mail: laura.seppanen@ttl.fi

H. Heikkilä

e-mail: Heli.Heikkila@ttl.fi

H. Ylisassi

e-mail: Hilkka.Ylisassi@ttl.fi

A. Kajamaa · P. Lahtinen

Faculty of Educational Sciences, University of Helsinki, Helsinki, Finland e-mail: anu.kajamaa@helsinki.fi

P. Lahtinen

e-mail: paivikki.lahtinen@uia.no 
such a culture and the prison staff's capacity to take a proactive stance in developing their collective work, a new facilitation method of humancentred co-evaluation (Hyytinen et al., 2019; hereafter HCCE) was applied in a low-security closed prison in Finland. The basic idea of the method is to support employees in their collective efforts to develop work practices by designing and implementing developmental tasks simultaneously with setting goals and finding ways to evaluate and learn from them. In addition to practices, the aim is also to develop the proactiveness of the prison personnel. Proactiveness means that employees take anticipatory actions to create change in how jobs, roles and tasks are executed (Grant \& Parker, 2009). Professionals' proactiveness also contributes to their well-being (Honkaniemi et al., 2015; Mäkitalo, 2005). Along with other formative interventions (see Chapter 8), the HCCE method can be seen as a design to stimulate proactivity by enhancing participants' capacity for innovation and reflection about the future. "Formative" here means that facilitators offer participants resources to engage in practical experimentation that can lead to generative, novel outcomes (Sannino et al., 2016). Simultaneously, HCCE helps staff "learn by evaluating" both outcomes and the collaborative processes of experimentation.

In a research project, ${ }^{1}$ employees, managers and researchers worked together on the so-called "Developmental tasks" or the development of innovations or experiments that are designed, implemented and evaluated collaboratively with the intention of transforming current working practices in the prison. These tasks were used to enhance two strategic aims of the Criminal Sanctions Agency (CSA) in Finnish prisons: the improvement of prisons' digital services and that activating rehabilitative work be included in the everyday duties of prison officers with inmates to reduce the risk of reoffending. By activating, reciprocal, rehabilitative work we mean the activities that prison officers do with inmates that are designed to change the prisoners' behaviours and prepare them for a crime-free life on the outside. The activities are aimed to

\footnotetext{
${ }^{1}$ Research project: 'Developing prison practices and enhancing transformational agency of employees by co-evaluating experiments' (2018-2020) (Kokeilujen osallistavalla arvioinnilla käytäntöjen uudistamista ja toimijuutta). Funding: Ministry of Justice, Finland (CSA) and the Finnish Institute of Occupational Health.
} 
motivate/activate the prisoner to engage proactively with their own transformation. This process must be a reciprocal process with both the prisoner and the officer working together with each other towards this common goal.

Historically, the latter has been a task of welfare staff employed in the prison-e.g. social workers, psychologists and educators-while prison officers have mainly been responsible for control and security. Involving prison officers in rehabilitative work can be viewed as a long-term sea change in the orientation, tasks and division of labour in Finnish prison services.

Our aim in this chapter is to describe how developmental tasks with rehabilitative work were co-designed, implemented and co-evaluated between the prison staff, management and researchers. This is the first time the HCCE method has been applied in prisons, and the main focus of the paper is the process of putting the method into practice.

The HCCE method, being part of a broad field of developmental evaluation (Patton, 2011), is about using evaluation for learning and development. Engeström and Sannino (2012) argue that all process theories of learning carry with them instructional assumptions of which facilitators need to be aware. Learners, in our case prison personnel, always proceed differently from what researchers or facilitators had planned. In formative developmental efforts, neither the outcome nor process is a universal given, and researchers do not have a monopoly over them (Engeström \& Sannino, 2010). The HCCE offers an expanded view for exploring development efforts and their consequences by viewing 'impact' as a qualitative learning challenge, rather than an accountable target to be achieved (Saari \& Kallio, 2011). Evaluation studies drawing from activity theory are not typically interested in causal connections but collect evidence of historically formed relationships, social processes and cyclical nature of change (Kajamaa, 2011).

We pay attention to the "gaps" in current prison activity that was uncovered by the developmental intervention and the HCCE method. However, we also explore the challenges/gaps that the HCCE method itself faces when implemented in prison culture. Following Engeström and Sannino (2012), we have taken these gaps between participants' activities and developmental interventions as potential resources with 
which to promote learning processes. At the end of the chapter, we discuss the gaps observed in the project, how they inform our understanding of the change taking place, and how researchers have considered the gaps in shaping the HCCE process.

The chapter proceeds as follows. The next section is an introduction to the HCCE method. Second, we will familiarise the reader with the main features of the Finnish prison system, including Prison A where the study took place. This leads on to presenting the developmental process as a narrative, examining first how developmental tasks were designed, implemented and co-evaluated at Prison A. At the end, we discuss the challenges or gaps found during the process, and conclude by highlighting the value of the HCCE method in systematic long-term developmental efforts.

\section{The Method of Human-Centred Co-evaluation (HCCE)}

The method of human-centred co-evaluation was recently developed by Eveliina Saari, Kirsi Hyytinen and their colleagues (Saari \& Kallio, 2011; Saari et al., 2018; Hyytinen et al., 2019) to support innovation in the digitalisation of services (developmental tasks), and embedding, disseminating and upgrading these in practice. A core device of the method is a multi-criteria evaluation framework through which the impact of an innovation (a local developmental task) can be considered (Fig. 9.1). The framework is a modification of the work by Djellal and Gallouj (2013) of pragmatist origin, although the conceptualisation of learning and development of the HCCE method is based on cultural historical activity theory (Hyytinen et al., 2019). ${ }^{2}$ The HCCE method instructs participants to consider the proposed innovation they have co-created together.

\footnotetext{
${ }^{2}$ A manual of the method is freely available in Finnish (Saari et al., 2018). It has spread into a nationally applied developmental evaluation method in citizens' digital help services, in school experiments and elsewhere. See https:/www.ttl.fi/wp-content/uploads/2017/12/kokeilut-kaytan toon-tyokirja.pdf.
} 


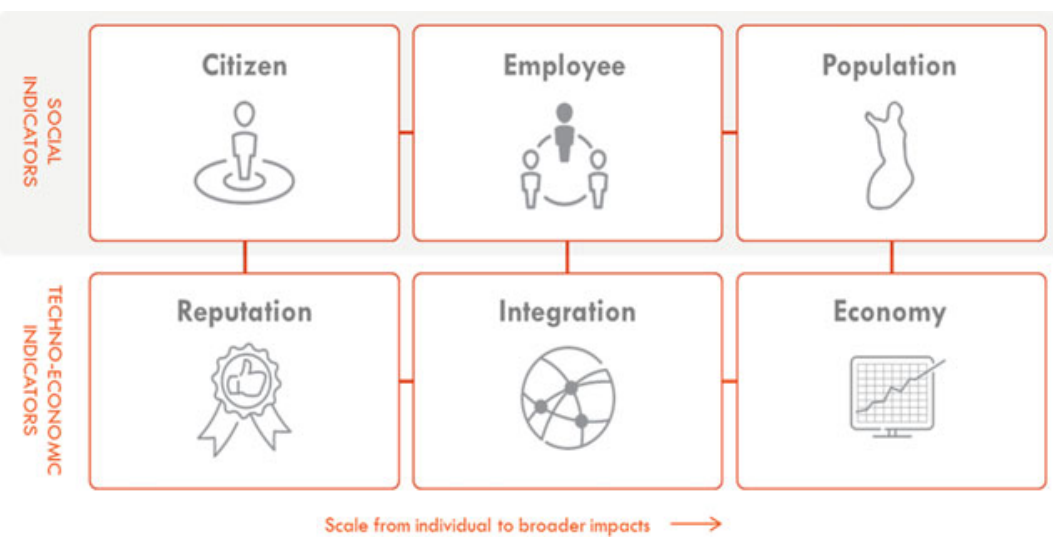

Fig. 9.1 Impact dimensions of multi-value evaluation framework (Hyytinen et al., 2019)

In the social indicators dimension on the citizen or service user (see Fig. 9.1, first quadrant), participants analyse the value of the product of the developmental task they have produced together from the viewpoint of an individual inmate. The emphasis is on client orientation and the significance of service for him or her. The second quadrant on employee directs the discussion to changes the innovation may bring about, changes in the content of work, including work roles, relationships, knowledge and tasks. The impact on clients/service users and employees captures value from the perspective of an individual or a small group of individuals, whereas the impact on population helps participants to elaborate on value from a wider perspective, such as of a specific geographical region or its population. In the techno-economic dimension, the focus is on the effects on brand image and on the reputation and visibility of actors involved in service development. The value of the developmental task in relation to many interlinked services and to the technology is evaluated in the integration dimension. With the last dimension, economy, the economic effects of the developmental task can be discussed by considering them from the perspectives of both a single actor or a group of actors and broader society. 
The HCCE process is supported by three facilitated workshops. In the first workshop, the participating employees and their supervisors brainstorm and choose one or a few ideas (or developmental tasks) that could respond to clients', employees' or the organisation's needs, after which they carefully design and prepare these. In the second middle-way workshop, the participants consider the impacts of developmental tasks from the user and the worker perspectives. In this phase, it is still possible to modify the developmental task and its criteria if necessary. The third co-evaluation workshop takes place after the experimentation has been put into practice to evaluate its impacts according to the six dimensions presented in Fig. 9.1 (Saari et al., 2018). In this workshop, the work developers, employees, service users and decision-makers are brought together to learn what has been achieved, and what should be accomplished and done in near future. In our study, only the first and third workshops were implemented.

The structure of HCCE is based on the aquarium technique (AaltoKallio \& Hakulinen, 2009) common in developmental efforts. Here participants alternate between discussing and listening as members either of an "inner circle" or "outer circle". In the third co-evaluation workshop this means that, first, the developmental task is co-evaluated with the framework (Fig. 9.1) by members of "the inner circle" consisting of those who had designed, implemented and used the proposed innovation. Participants then evaluate how the developmental task has succeeded in each of the six dimensions. The aim here is to create new meanings for the developmental task and see new opportunities to develop it (Hyytinen et al., 2019). We will come back to the HCCE method after taking a look at the Finnish prison system, Prison A and the prison officers' rehabilitative work with prisoners.

\section{Features of Finnish Prison Services and "Prison A"}

In Finnish prisons, prison officers are the ones who most often see inmates while taking care of many practical and control tasks in prison wings. They may advise inmates to attend prison activities and make contact 
with social workers, psychologists, priests or instructors when needed. Health care professionals, while present in prisons, operate outside the prison system in a national unit responsible for prisoner health care. Other rehabilitative staff are officials of the Correctional Sanctions Agency (CSA) in Finland. Senior officials ${ }^{3}$ are responsible for working with inmates in their progress with sentence plans and partly act as prison officers' supervisors. Sentence plans are made outside prison in a regional assessment centre of CSA. Besides a director, a prison has two assistant directors, one of which is responsible for security, and the other for rehabilitative programmes for inmates. We can see how the divide of welfare and control is built into the division of labour.

Prison A is a closed low-security prison with approximately 120 male inmates and staff about 80 people. It is known for its culture of good and fluent interaction between inmates and staff. The assistant directors meet twice a week with senior officials. Senior officials meet prison officers occasionally in wings, during coffee breaks and in annual development work discussions, but they do not have the formal right to make supervisory decisions. The prison officers do not have meetings with each other or with other professionals, apart from annual training programmes.

Inmates may voluntarily work or participate in a wide range of educational or rehabilitative activities. Remand prisoners stay for several weeks up to a maximum of a few months in the prison which makes longterm rehabilitation work difficult. Since 2018, the prisons have been collecting written feedback from inmates when they leave the prison of their overall experience of the prison. At Prison A, inmates' responses so far have been positive, although there were negative reports of the first phase of entrance to prison.

To enhance rehabilitative work, the CSA started a long-term transformation of occupational roles in prisons. In 2019, a new form of education was launched for officers to become "responsibility workers" who in the future would do most of the rehabilitative work with a particular inmate, including sentence plan work. Senior officials, in turn, would guide and supervise these responsible workers in their work with

\footnotetext{
3 The formal title is senior criminal sanctions official.
} 
inmates. Some officers would continue to work without being responsible workers. This future planned structure, while aimed at supporting rehabilitative work, is now causing uncertainty and feelings of injustice, not least because the salary categories will be renewed accordingly. In this situation, it was necessary for Prison A to make clear that rehabilitative work concerns everyone in the prison, regardless of their occupational status.

\section{Rehabilitative Work with Prisoners}

This study originates from a long-term R\&D collaboration between the Correctional Sanctions Agency in Finland and the Finnish Institute of Occupational Health. Previously, the ombudsman of the Finnish Parliament had remarked that in Finnish closed prisons, inmates remain too passive and isolated in their cells, and that the CSA needed to pay attention to this problem. This corresponded with the CSA's strategic aim of enhancing more dialogic and innovation creation/activating elements in prison activities for inmates. The way to do this was to develop prison officers' rehabilitative work (in Finnish, the word is lähityö literally meaning "near work") with prisoners, by promoting local and national developmental tasks that were partly designed and implemented by prison staff.

Supporting inmates rehabilitation and capacity to desist from future criminal activity are central to a prison's aim (Ylisassi et al., 2016, p. 74). For officers' rehabilitation work is about making contact with the prisoner and hereby building trust, and guiding inmates to other health and welfare staff for further support. Combining a rehabilitative approach while maintaining control is not easy and requires prison staff sensitivity, knowing prisoners (dynamic security) and situational awareness. The staff's descriptions of turning difficult situations into successes by using an activating approach explain the opportunities of rehabilitative work (Ylisassi et al., 2016).

Next is an illustration of how a developmental task was co-designed, implemented and co-evaluated with the HCCE method at Prison A. 


\section{The HCCE Facilitation of the Developmental Task Process at Prison A}

\section{Preparation}

The HCCE project at Prison A proceeded on three levels: (1) the national Advisory Board of the project, which decided on a suitable prison and Prison A agreed to participate in the project, (2) the local collaboration between researchers and prison employees (an assistant director and a social worker) responsible for the HCCE project in the prison and (3) the HCCE workshops.

A lot of preparation was needed. First, the researchers (the three authors from FIOH of the chapter) presented the project idea to a group of managers, senior officials and officers at Prison A. It became clear that there was a good culture of rehabilitative work, but they had not yet experimented with new practices nor systematically developed their structures for supporting rehabilitative work. The project thus needed to start with designing the developmental tasks. The practices of "the incoming phase", after the inmate enters the prison until they settle in an allocated wing, was chosen as a prison activity with which staff could experiment.

The developmental tasks were designed in two workshops, after which they were subjected to pilot testing for three months by several officers. The core workshop participants were chosen from among prison officers who were mainly responsible for the security and control of the prison and were increasingly supposed to do rehabilitative work.

Second, individual and group interviews with the personnel of Prison A were carried out so that researchers could become familiar with people in the prison, get to know their work and their views about ongoing changes, especially concerning rehabilitative work, and to collect suitable material (mirror data-see Chapter 8) for the design workshop. 


\section{The Design Workshop}

Third, the design workshop was planned. The researchers collected excerpts from the aforementioned interviews that depicted the current situation and what was aspired to in the future. These were presented in the form of brief sentences or concepts (Virkkunen, 2007) that were aimed at illustrating the core purpose of prison officers' work activity. This work activity included excerpts that illustrated "relaying information between different professionals and between professionals and the inmate", "getting to know the inmate" "prisoners and professionals getting along with each other". The material presented aimed to demonstrate the way in which prison officers currently attempt to activate inmates to engage in the rehabilitation process, influence their thinking and generally prepare them for reintegration back into society. The materials aimed to demonstrate where there were areas for development and an expansion of current work activity.

The former with its aim was articulated as "relaying information and learning to know the inmates - getting along during prison time" and the latter as "Activating inmates to talk, influencing the thoughts - > getting along in society". They indicate not only a difference or gap between different aims or purposes, but also a temporal gap between now and the future.

The interview excerpts and the model concepts were then shown to participants in the design workshop to prompt discussion about ideas (or tasks) required to address some of the challenges illustrated within the excerpts and model concepts. In addition to the researchers, the participants of the design workshop were prison officers, senior officials, social workers and assistant directors. Service users such as prisoners could be asked to join the HCCE workshops in theory, but in this study, it was not possible for reasons related to research ethics.

In the design workshop, discussion around the current and future model concepts suggests that the transformation of prison work is more complex than merely improving separate processes-rather, it is more likely to be a systemic change that transforms not only individual officers' practices and work orientation, but also the roles and division of labour of the prison. The discussion within the workshop raised new 
perspectives, such as: control is not separate from activating rehabilitative work: rather, the latter builds dynamic security in the prison. It was argued that a functioning security culture of a prison is a precondition for rehabilitative work to be successful. The discussions included many critical expressions as well: e.g. members of organised crime can strengthen the criminal culture and thus hamper rehabilitative work in prison departments.

An illustration of a prisoner's path at the incoming phase when the prisoner is admitted to prison was also used to help design developmental tasks in the workshop. The discussion was facilitated by asking participants to explain how and wherein the pathway information exchange took place, how participants got to know the inmates and got them to talk. When workshop participants reflected on the inmates' path, the researchers emphasised the need for participants to specify in the pathway where service actions took place. This prompted participants to begin looking at improving communication among prison functionaries. They explored in particular how information gained during different steps could better reach relevant functionaries in the prison wings at the point that prisoners are moved from custody to their respective wings. The researchers' aim was to help participants discuss "what we can do", rather than "what those outside prison should do".

As an outcome of the design workshops, two new local developmental task ideas came out. The first was that participants decided officers could begin recording inmates' behaviour in a new digital sentence plan. Here, the officers saw an opportunity to make their rehabilitative work more visible both at prison, region and national levels of prison services. Recordings could give more weight to prison officers' perspectives in decisions concerning the inmates. The second developmental task was to redevelop the induction programme that introduced inmates to their permanent cell/wing when they left the custody suites after first entry into the prison. This addresses an issue identified as problematic by inmates and thus indirectly gives voice to the inmates. In the recording task, officers wrote down both positive and negative things about inmates' behaviour and initiatives for their sentence plans. While the aim of both developmental tasks is to improve communication between inmates and staff and within and between occupational 
groups, we here have concentrated on recording developmental task for simplicity.

The collaboration between the prison staff and researchers was crucial for the success of the project. They jointly have at least two or three encounters per month, either at Prison A or online, for planning the sequence of each step. The key contact points in the prison responsible for liaising with the researchers (a social worker and an assistant director) usefully commented on the researchers' plans, made suggestions, motivated people in the prison to participate and were responsible for organisation of and communication about the workshops and the developmental tasks.

\section{Implementation of the Developmental Tasks}

After a pilot project involving some officers, the implementation of the developmental tasks started by introducing them in the official annual training programme of all officers at Prison A. The important transition of leadership from external researchers to prison happened in this phase. Researchers still supported the training with a PowerPoint presentation about the developmental tasks, and they observed this part of the training online but participated with only minor comments at the end about the forthcoming co-evaluation workshops.

The training consisted of useful dialogues about the developmental tasks and critical voices were also heard. For example, a representative of the regional assessment centre participated by giving a talk about the importance of recording, i.e., that the assessment centre needs to make important decisions about an inmate's move from high security to an open (half-way) prison. Good decisions require that there are grounds and evidence for those decisions. A record of the behaviour and needs of the prisoner, recorded digitally of everyday life of the prisoner on the prison wings, as witnessed by officers, is an important source of facts for decision making that can be shared between services.

During the training, the prison assistant manager was expecting everybody to participate by putting the developmental tasks into practice. This is a hierarchical top-down mandate through which an employer 
has a "direction right" to tell employees what they need to do. This is in opposition to the principles of the HCCE and many other developmental methods in which participation is voluntary and an employee's autonomy is respected, even encouraged. This cultural gap between employees' autonomy and hierarchy exists in developmental efforts in all salaried work but seems to be particularly strong in hierarchic organisations such as prison services. We will come back to this in the discussion.

After the training, the researchers devised paper forms for prison staff to record their experiences of using the new recording system, and the prison managers formulated the necessary documents for the task of recording. Most officers implemented the developmental task and recorded their feedback about them on the paper forms. Some refused to do so "before this extra task is considered in their salary". During the implementation, a social worker interviewed inmates about the developmental tasks. Researchers condensed all the experiences collected for use in the co-evaluation workshop to come. They also developed prompts or assisting questions to unpick each of the dimensions of the evaluation framework (Fig. 9.1) for the co-evaluation workshop.

\section{Co-evaluation Workshop}

The workshop started with brief presentations about the developmental task (the digital sentence plan), and the prison staff's and inmates' feedback about it. After that, the inner circle, consisting of five prison officers together evaluated it in the light of each evaluation framework dimension (Fig. 9.1). They were asked to consider how the developmental task would generate value from the perspective of each dimension. Participants were guided to consider both positive and negative changes as well as anticipated and unanticipated effects. The questions were tailored to this developmental task at Prison A.

In the first client/prisoner dimension, the questions for the inner circle of the workshop included: What are the benefits and harms of recording for the inmates? How useful are officers' recordings for inmates in reaching the aims of their sentence plans? What changes do inmates 
see in their relationship and communication with prison staff? Does the recording affect relations between inmates, and how?

The impact on employee focuses on changes in the content of work, including work roles, relations, knowledge and tasks. The guiding questions were: How has the developmental task affected the prison officer's role? What are the outcomes of recording on trust-building and activation with inmates? How has the developmental task affected officers' sense of personal safety? Does the recording fulfil its promise of making the officers' rehabilitative work with inmates more visible to others?

With the dimension of population the aim is to steer the discussion to evaluate the recording task from the perspective of a specific geographical region with its population. How can the recording affect an inmate's risk of returning to prison? The reputation was enquired about by asking: how could the developmental task influence the public image of Prison A and national prison services?

The aim of the integration dimension is to provide understanding on how the developmental task aligns with other prison services as well as with data systems. In our case, the main questions were: To what extent has the recording improved the information flow from an officer to other prison staff? To what extent can recording support inmates' path to a crimeless life and reintegration into society? We need to consider here that digital services will be implemented in all Finnish prisons within the next five years or so. How does the task of recording inform the development of digital services in prisons?

Evaluation of economy focuses on new potential resources and savings, for example. How do officers' recordings impact the economy and costeffectiveness of Prison A? How does it affect the allocation of resources such as space, time use and workforce?

After the inner circle had evaluated the developmental task according to the six quadrants in Fig. 9.1, and the questions sketched above, the outer circle came to the fore. It consisted of people who could promote the developmental task by improving or spreading it into wider use. It included actors from the regional office and the evaluation centre of CSA. Collaborators from other services could also be invited. Now the inner circle only listened. The outer circle discussed what they had heard and what they could conclude from the inner circle's evaluation. 
They summed up their discussion by writing down their suggestions and presenting: what lessons have been learnt? what should be done next? and how could participants in the outer circle contribute by embedding, spreading or improving the task?

Finally, the inner circle discussed, complemented and decided on suitable future actions, based on the outer circle's proposals. They could also remove some of the suggestions and add their own. The co-evaluation workshop ended by suggesting the ways forward. In this workshop, training and preparing a common set of simple guidelines for recording were the next steps.

\section{Discussion and Conclusion}

In our HCCE research project, there was a national strategy to develop rehabilitative work in prison services. This need drove forward the collaboration between the prison authorities and researchers that would become HCCE. Without this need, the HCCE project at Prison A and the developmental tasks that arose from it, would not be there. However, the alignment of developmental, participatory research with this political strategy also increases the complexity of the researchers' role: besides being a facilitator, they need to find a balance between strategic topdown-driven change and employee-driven innovation. Here, we have discussed the HCCE process in terms of gaps observed during the process. These are gaps both in the current prison activity but also in applying the HCCE method itself. The HCCE process has helped us focus on the following gaps:

\section{The Gap Between Control and Rehabilitation in Prison Officers' Work}

This reflects the general fundamental and historical contradiction of prison services between security (punishment) and well-being (care) (Laine, 2011). This gap is visible in the division of labour in the prison between those who have security versus rehabilitative responsibility. 
However, our study revealed how rehabilitative work is not contrary to security and control, but rather builds on it. Security is not set aside when there is a greater emphasis on care. The notion of dynamic security is an important mediator between control and rehabilitation. For officers, rehabilitative work may find its justification precisely through dynamic security. The developmental task process suggests that we are not only dealing with a transition from control to rehabilitative work emphasising rehabilitation and welfare. Both control and enhancing security for individual inmates and staff members should be integrated into the design, implementation and evaluation of rehabilitative work. There is a need to find solutions through which both security and rehabilitative work can simultaneously be enhanced.

\section{The Gap Between Hierarchic and Participatory Cultures of Development}

The HCCE method carries with it an assumption of a participatory, developmental culture that nurtures employees' proactiveness and learning. The traditional hierarchic culture of prison services is poor in encouraging employees' initiatives and innovation. It is hard for employees to activate and empower their clients (such as inmates) if they work in strongly hierarchical cultures (Ylisassi et al., 2016). Researchers and facilitators need to be aware of how different cultures may create pressures for local workers. In the HCCE project, this gap was considered by trying to create dialogues between the needs experienced by prison officers (invisibility of their work; lack of influencing possibilities) and the Criminal Sanction Agency's official rehabilitative work strategy.

\section{The Gap Between the Novel Recording Task and Prison Officers' Traditional Tasks}

The recording task nudges officers towards writing down things about the inmates. However, they are being asked to do so at a time when they feel they lack time, motivation and legitimacy to do this. In addition, the HCCE method with its aim of systemic evaluation also requires 
recording-without making visible the pros and cons of the developmental task as participants see it, the evaluation remains superficial. The recording of the developmental task process thus poses a double challenge of recording for participants (see section on implementation of the developmental tasks earlier). This gap was tackled with the very idea of encouraging people to try out the new model of working. In the training session, prison officers were motivated by hearing how important their recordings were for the regional assessment centre. The promise of having a voice in the co-evaluation workshop gave prison officers motivation to write down their experiences about the developmental tasks.

Cerf (2011) describes participatory research as a joint production of an "artefact" between a researcher and the practical partners in the researchaction process. The developmental tasks in our case are such artefacts. They evolve along with the interactions, and the change proceeds as different actors adopt or modify tasks and make them exist for themselves. In action research type of developmental projects, researchers need to pay attention to the different qualities of knowledge produced in the process (Cerf, 2011). It remains to be seen if the officers' developmental tasks will finally exist "for themselves", and if so, in what way they are redefined, made meaningful and evaluated. Even "failed" developmental tasks can be generative for collective learning (De Keyser et al., 2019).

The developmental tasks are not about rehabilitative work only: they also enhance and require multi-professional collaboration between prison staff. Recording observations supports all communication and possibly collaboration within prison and other services (see Chapter 2).

We may see recording and communication as parts of the increasing trend of datafication (Thompson, 2017) and digital technology in prison services (Johnson \& Hail-Jares, 2016). Digitalisation enables enhanced information collection and knowledge production for better awareness of work practices. This means better decision-making for managers but also prison staff may access information that is useful for their own work. In prison services, digital information through recording can be used for producing public value for society.

The outcomes of the HCCE project in terms of new practices and employees' proactiveness remain to be studied. The HCCE method 
provides a welcome theory-based practical complement to implementation and evaluation in formative interventions and it is also a contribution to the wider literature on developmental research. We see that the HCCE process benefits from identifying developmental gaps in and between research and prison services and learns from them. The sixdimension framework (Fig. 9.1) can be used to give voice to differing interests and influence the future actions to be taken in prisons and elsewhere. Some work is still required to structure the argument of what the HCCE method adds to the field.

\section{References}

Aalto-Kallio, M., \& Hakulinen, H. (2009). Arviointiakvaario-osallistuva menetelmä kaikkien hyödyksi [Evaluation aquarium-A participatory method for the benefit of all. In Finnish]. Terveyden edistämisen lehti Promo, 59, 36.

Cerf, M. (2011). Is participatory research a scientific practice? Journal of Rural Studies, 27(2011), 414-418.

De Keyser, B., Guiette, A., \& Vandenbemt, K. (2019). On the dynamics of failure in organizational change: A dialectical perspective. Human Relations, 2019 online first.

Djellal, F., \& Gallouj, F. (2013). The productivity in services: Measurement and strategic perspectives. The Service Industries Journal, 33(3-4), 282-299.

Engeström, Y., \& Sannino, A. (2010). Studies of expansive learning: Foundations, findings and future challenges. Educational Research Review, 5, $1-24$.

Engeström, Y., \& Sannino, A. (2012). Whatever happened to process theories of learning? Learning, Culture and Social Interaction, 1(2012), 45-56.

Grant, A. M., \& Parker, S. K. (2009). Redesigning work design theories: The rise of relational and proactive perspectives. The Academy of Management Annals, 3(1), 317-375.

Honkaniemi, L., Lehtonen, M. H., \& Hasu, M. (2015). Wellbeing and innovativeness: Motivational trigger points for mutual enhancement. European Journal of Training and Development, 39(5), 393-408.

Hyytinen, K., Saari, E., \& Elg, M. (2019). Human-centered co-evaluation method as a means for sustainable service innovations. In M. Toivonen 
\& E. Saari (Eds.), Human-centererd digitalization and services (pp. 57-75). Singapore: Springer Nature.

Johnson, R., \& Hail-Jares, K. (2016). Prisons and technology: General lessons from the American context. In Y. Jewkes, B. Crewe, \& J. Bennet (Eds.), Handbook on prisons (pp. 284-305). New York: Routledge.

Kajamaa, A. (2011). Unraveling the helix of change: An activity-theoretical study of health care change efforts and their consequences. Helsinki: Unigrafia.

Laine, M. (2011). Rankaisu ja kuntoutus [Punishment and rehabilitation. In Finnish]. In R. Lavikkala \& H. Linderborg (Eds.), Rikosseuraamustyön kehittämisen kysymyksiä. Tampere: Rikosseuraamusalan koulutuskeskus 2/2011.

Mäkitalo, J. (2005). Work-related well-being in the transformation of nursing home work. Acta Universitatis Ouluensis D Medica 837, Oulu University Press, Oulu.

Patton, M. Q. (2011). Developmental evaluation: Applying complexity concepts to enhance innovations and use. New York: The Guilford Press.

Saari, E., \& Kallio, K. (2011). Developmental impact evaluation for facilitating learning in innovation networks. American Journal of Evaluation, 32(2), $227-245$.

Saari, E., Hyytinen, K., Hasu, M., Hyypiä, M., Korvela, P., Käpykangas, S., Leväsluoto, J., Melkas, H., Nordlund, A., Pekkarinen, S., \& Toivonen, M. (2018). Kokeilut käytäntöön -työkirja [Experiments into practice. Manual. In Finnish]. https://www.ttl.fi/wp-content/uploads/2017/12/kok eilut-kaytantoon-tyokirja.pdf.

Sannino, A., Engeström, Y., \& Lemos, M. (2016). Formative interventions for expansive learning and transformative agency. Journal of the Learning Sciences, 25(4), 599-633.

Thompson, T. L. (2017). Datafication of professional practices: A posthuman exploration of new accountabilities and fluencies. Paper presented at the 10th Conference on Researching Work and Learning, Grahamstown, South Africa.

Virkkunen, J. (2007). Collaborative development of a new concept for an activity. @ctivités revue éléctronique, 4(2), 158-164.

Ylisassi, H., Seppänen, L., Uusitalo, H., Kalavainen, S., \& Piispanen, P. (2016). Aktivoiva lähityö. Vankiloiden valvonta-ja ohjaushenkilöstö vuorovaikutuksellista lähityötä kehittämässä. [Activating interactive work. Prison personnel developing rehabilitative interactive work with prisoners. In Finnish, with English and Swedish summaries]. http://www.rikosseuraamus.fi/material/ attachments/rise/julkaisut-risenjulkaisusarja/qmR5zNYVd/RISE_2_2016_A ktivoiva_lahityo_WEB.pdf. Rikosseuraamuslaitoksen julkaisuja 2/2016. 
Open Access This chapter is licensed under the terms of the Creative Commons Attribution 4.0 International License (http://creativecommons.org/ licenses/by/4.0/), which permits use, sharing, adaptation, distribution and reproduction in any medium or format, as long as you give appropriate credit to the original author(s) and the source, provide a link to the Creative Commons license and indicate if changes were made.

The images or other third party material in this chapter are included in the chapter's Creative Commons license, unless indicated otherwise in a credit line to the material. If material is not included in the chapter's Creative Commons license and your intended use is not permitted by statutory regulation or exceeds the permitted use, you will need to obtain permission directly from the copyright holder.

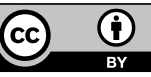

